\title{
COGNITIVE IMPAIRMENTS IN PATIENTS WITH TREATMENT RESISTANT EPILEPSY UNDERGOING COMPLEX REHABILITATION
}

\author{
Korostiy Volodymyr', Blazhina Iryna ${ }^{2}$ \\ ${ }^{1}$ Kharkiv National Medical University \\ ${ }^{2}$ Bukovinian State Medical University \\ https://doi.org/10.35339/ic.8.2.123-129
}

\begin{abstract}
Background. The study of features of comorbid pathology in patients with epilepsy is of particular interest due to the high prevalence of this pathology and a significant impact on the quality of life of patients and their social adaptation. Aim. The aim of the research was to detect versatile cognitive impairments and affective disorders in epilepsy, and to study the results of cognitive training and psychoeducation. Materials and methods. The theoretical analysis of modern scientific researches in the field of cognitive and affective impairments during epilepsy was carried out. We studied the features of clinical and psychopathological manifestations in patients, suffering from epilepsy. The study covered 146 patients $(85$ men and 61 women) who were in inpatient care. The following psychodiagnostic techniques were used: the MOCA test, the Toronto Cognitive Assessment (TorCA), the MiniMult test, the Munsterberg test, the quality of life scale, the Hamilton scale of depression and anxiety. Results. This publication offers the results of a study of cognitive and affective disorders the quality of life in patients who suffer from epilepsy and the results of online cognitive training and psychoeducation. We found cognitive decline in $88 \%$ of patients with epilepsy and improvement of cognitive functions by methods of non-pharmacological correction. Conclusions. Affective and cognitive disorders significantly affects the quality of life of patients, their ability to work and socialization. The conducted research showed that compared to the control group of healthy persons, patients with epilepsy showed improvement in their cognitive decline, anxiety and depressive disorders. Cognitive online training appeared to be effective for the patients with epilepsy.
\end{abstract}

Keywords: Epilepsy, Cognitive disorders, Affective disorders, Cognitive online training.

\section{Introduction}

Epilepsy is a chronic, neuropsychiatric disorder with diverse etiology characterized by persistent predisposition to epileptic seizures, as well as the neurobiological, cognitive, psychological, and social consequences of this condition.

Epilepsy is one of the most common neuropsychiatric disorders, affecting about 65 million people worldwide. As epilepsy prevalence increases with age, $25 \%$ of the first detected cases are diagnosed at the age of 65 or over. Various neuropsychiatric and somatic conditions, such as traumatic brain injury, cerebrovascular

\footnotetext{
Corresponding Author:

Iryna Blazhina, $\mathrm{MD}, \mathrm{PhD}$, Assistant

of the Department of Neurological, psychiatry

and medical psychology, Bukovinian State

Medical University, Kharkiv, Ukraine.

E-mail: blazhina9@gmail.com
}

disorders, Alzheimer disease, increase the incidence of epilepsy exponentially [1].

The disease is characterized by heterogeneity of clinical manifestations. In all the variety of mental pathology, there are cognitive disorders, epileptic psychoses, depressive, anxiety and obsessive-compulsive disorders, behavioural disorders, and epileptic encephalopathy. Mental disorders in epilepsy occur more often than in the general population. According to some researchers, about a third of people with epilepsy suffer from comorbid mental disorders: depression, anxiety, dysphoria, which greatly complicate the course of the underlying disease and impair quality of life.

Some researchers believe that mental and behavioural disorders are consequences of epilepsy [2], while others admit the two-way causal relationship between them $[3,4]$. Patients with comorbid disorders are more prone to seek 
medical assistance, including a higher suicide rate, lower adherence to treatment recommendations, lower quality of life, and lower control of epileptic seizures [5].

Cognitive dysfunction in epilepsy significantly deteriorates the quality of patients' life, their social functioning and adherence to treatment. The main cognitive functions include perception, attention, memory, praxis, language, executive functions, and social intelligence.

In our opinion, a cure for patients with epilepsy should include not only medication and surgical treatment but also psychotherapeutic methods, namely: psychoeducation and cognitive training. Psychoeducational activities include the dissemination of knowledge about epileptic seizures, treatments, comorbid conditions and life problems. Most psychoeducational interventions involve education and training.

\section{Purposes, subjects and methods:}

2.1. Purpose of the research was to detect versatile cognitive impairments and affective disorders in epilepsy, and to study the results of cognitive training and psychoeducation.

\subsection{Subjects \& Methods}

The features of clinical and psychopathological manifestations were investigated in patients with epilepsy, monitored in 2017-2020 at the Municipal Medical Institutional of Chernivtsi Regional Psychiatric Hospital. The cognitive decline study covered 146 patients $(85$ men and 61 women) with epilepsy.

Further, following the eligibility criteria, 96 patients were selected. The study complied with the principles of medical ethics and deontology. The research included the patients aged 18-65 who were diagnosed with epilepsy (F06.63, F06.73, F06.83, and F07.83). Their distribution by age and gender is given in Table 1 .

Table 1

Age and gender distribution

of patients with epilepsy monitored in the study (\%)

\begin{tabular}{|c|c|}
\hline \multicolumn{2}{|c|}{ Patients' age $(\mathrm{n}=146)$} \\
\hline $18-20$ & 8,22 \\
\hline $21-30$ & 15,75 \\
\hline $31-40$ & 24,66 \\
\hline $41-50$ & 21,92 \\
\hline $51-60$ & 21,23 \\
\hline $61-65$ & 8,22 \\
\hline \multicolumn{2}{|c|}{ Patients' gender } \\
\hline Men & 58,2 \\
\hline Women & 41,8 \\
\hline
\end{tabular}

The research included three stages. At the first stage, 146 patients, diagnosed with epilepsy, were examined. At the second stage, eligibility criteria were applied to set up three groups of patients PG1, PG2 and PG3. The first group comprised 30 patients, who completed a cognitive training. Psycho-correctional sessions and psychoeducation were also applied to the first group of patients. The second group included 33 patients, who completed a cognitive training. 33 patients of the third group were given standard therapy. In addition, a control group of healthy persons (PG4) was set up for comparative purposes. They completed a cognitive training. At the third stage, patients' and healthy persons' control tests were performed three months after the application of corrective methods.

The methods applied included clinicalpsychopathological, psycho-diagnostic, socialdemographic and statistical. The psycho-diagnostic method was based on the use of Montreal Cognitive Assessment (MoCA) (Nasreddine Z.S. et al., 2005 p.) [22, 23, 24], Toronto Cognitive Assessment (TorCA), selective attention diagnostics involved Munsterberg's test, the examination of individual personalities and mental conditions involved a shortened version of the Minnesota Multiphasic Personality Inventory, or MMPI (1937), developed by J. C. Kincannon, (MiniMult, 1968) [25], the examination of the range of psychoemotional states was carried out using the Hamilton Rating Scale for Depression (HRDS), Hamilton Anxiety Rating Scale (HARS) (1960) [26, 27], the quality of life was assessed using the method suggested by Mezzich J., Cohen N., Liu J., Ruiperez M., Yoon G. (1999).

The collected data were statistically processed using Excel and Statistica 7.0 for Windows software package. Processing also included the use of Student's t-test, Mann-Whitney U-test, Kruskal-Wallis $\mathrm{H}$ test, Wilcoxon signed-rank test, and Spearman's rank correlation coefficient.

\section{Results \& Discussion}

According to MoCA findings, the patients with epilepsy showed cognitive decline, the average score was 20.72 , where as healthy persons' average score was 27.36. Test data are given in Table 2.

According to the findings of Toronto Cognitive Assessment (TorCA), conducted on 27 patients: $88.9 \%$ had cognitive impairments, $7.4 \%$ had borderline results, and only $3.7 \%$ of patients didn't show any cognitive impairments. Overall, the advantages of applying Toronto Cognitive 
Patients' cognitive functions assessment data (MoCA Test)

Table 2

\begin{tabular}{|l|c|c|c|}
\hline \multicolumn{1}{|c|}{ Criteria } & $\mathrm{PG}_{\text {total }}(\mathrm{p})(\mathrm{n}=146)$ & $\mathrm{PG} 4(\mathrm{p})(\mathrm{n}=33)$ & Mann-Whitney U-test \\
\hline Management & 3.09 & 4.81 & $<0.001$ \\
\hline Name & 2.74 & 3 & 0.012 \\
\hline Attention & 1.28 & 1.87 & $<0.001$ \\
\hline A series of letters & 0.67 & 0.81 & 0.104 \\
\hline A series of subtractions & 2.03 & 4.81 & $<0.001$ \\
\hline Speech & 1.53 & 2 & $<0.001$ \\
\hline Speed & 0.74 & - & 0.468 \\
\hline Abstract thinking & 1.08 & 1 & 0.001 \\
\hline Deferred reproduction & 1.97 & 3.09 & 0.011 \\
\hline Orientation & 5.68 & 6 & $<0.001$ \\
\hline Total score & 20.72 & 27.36 & \\
\hline
\end{tabular}

The difference between the groups is significant at $p<0.05$.

Assessment (TorCA) include high sensitivity of the scale and the possibility to study particular cognitive functions, while its disadvantage is a complicated procedure.

Cognitive dysfunction as found in $88 \%$ of patients, mild dementia in $48 \%$, moderate dementia in $24 \%$ and severe dementia in $16 \%$. MoCA test results are presented in the diagram (Fig. 1).

Hamilton Depression Rating Scale (HDRS) revealed that $38 \%$ had symptoms of depression, $28 \%$ had mild situational or neurotic depression, $8 \%$ had moderate depression, and $2 \%$ had severe depression.
The distribution of affective disorders in patients with epilepsy are presented in the diagram (Fig. 2).

Hamilton Anxiety Rating Scale (HARS) showed that $20 \%$ of patients had severe anxiety, and $16 \%$ had the symptoms of anxiety.

This study was conducted using the Quality of Life Scale to determine the patients' quality of life. Unexpectedly, a part of the patients evaluated it very high, with the signs of cognitive decline and an objectively reduced level of functioning. A direct correlation between the degree of cognitive decline and subjective assessment of the

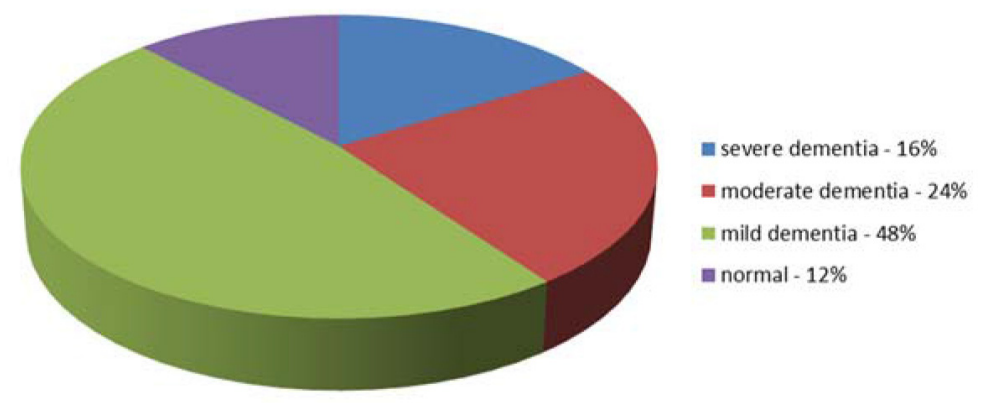

Fig. 1. Cognitive impairments in patients with epilepsy

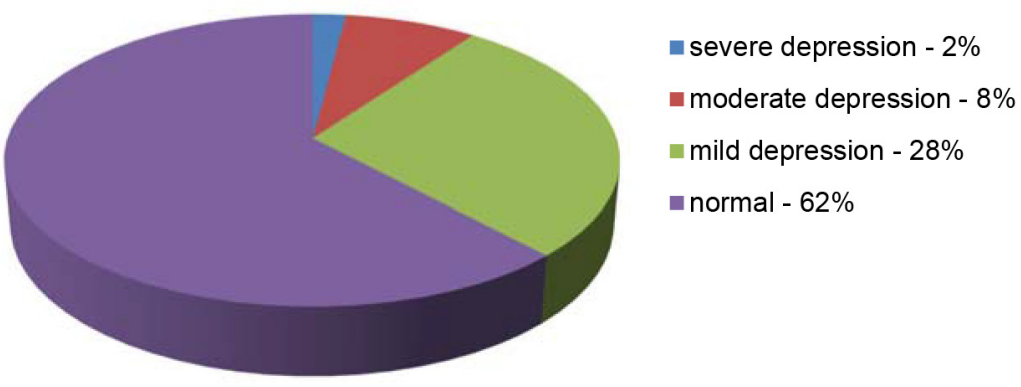

Fig. 2. Affective disorders in patients with epilepsy 
quality of life was found: the highest estimation of the quality of life was observed in the patients with more severe cognitive dysfunction. The average rate among all examined persons was 69.45 out of $100,78.60$ were the results of healthy persons (Table 3).
The group of patients who completed the cognitive training course only (PG2) also showed certain improvement - by 0.73 points, unlike the group of patients who underwent standard therapy only (PG3) - their indicators fell by 0.22 points. Selective attention improvement was observed:

Table 3

Initial cognitive functions, selective attention, anxiety level and depression test results

\begin{tabular}{|l|c|c|c|c|}
\hline \multicolumn{1}{|c|}{ Criteria } & $\mathrm{PG}_{\text {total }}(\mathrm{p})(\mathrm{n}=146)$ & $\mathrm{PG} 4(\mathrm{p})(\mathrm{n}=33)$ & Student's t-test & Mann-Whitney U-test \\
\hline Quality of Life Scale & 69.45 & 78.60 & 0.001 & 0.002 \\
\hline Münsterberg's test & 7.72 & 21 & - & $<0.001$ \\
\hline Hamilton Anxiety Rating Scale & 14.17 & 10.33 & - & 0.052 \\
\hline Hamilton Depression Rating Scale & 7.14 & 3.81 & $<0.001$ & $<0.001$ \\
\hline
\end{tabular}

The difference between the groups is significant at $\mathrm{p}<0.05$.

The above data showed that the values of Hamilton Anxiety Rating Scale and Hamilton Depression Rating Scale indicators are higher in patients with epilepsy than in healthy persons: $14.17-10.33$ and $7.14-3.81$, respectively. Munsterberg's test also showed significant decline in selective attention -7.72 in patients with epilepsy and 21 - in healthy persons.

During the pandemic of COVID-19, the patients were provided with the access to the online version of cognitive training, which is extremely important for improving their cognitive functions. Preparing patients for online training, we faced some technical difficulties. It took about two weeks to adapt to the resource. Some patients were unable to use the resource due to technical issues, lack of computer skills, or the level of their education. In general, the resource is easy to use. Short-term results may fluctuate, however, with long-term use of the resource there is a positive trend, in the group as a whole and in particular participants. Compared with the control group, patients with epilepsy had a greater interest in training and lower number of absences.

The data of Table 4 point to a more significant improvement of cognitive functions in the group of patients who completed a cognitive training course and psychoeducation (PG1) - by 1.4 points.
PG1 - by 0.63 , PG2 - by 0.27 , PG3 - by 0.15 . Anxiety declined in PG1 - by 11.45 , PG2 - by 4.21, while in PG3 it increased by 2.61. Positive dynamics was found according to the Hamilton Depression Rating Scale: PG1 - by 1.7, PG2 - by 2.32 , and in PG3 - 2.49. The subjective assessment by patients of the quality of their life rose in all three groups PG1 - by 2.77, PG2 - by 1.21, PG3 by 1.0 , which may indicate the improvement of the general state in all three groups. The above data may be used to confirm the efficiency and effectiveness of the cognitive training for the patients with epilepsy and the benefits of its combination with psychoeducation techniques.

Pathogenetically, epileptic system forms with the presence of several functionally different zones and determinant foci, the formation of secondary and tertiary foci, including mirror foci, which leads to a pronounced rearrangement of cytoarchitectonics of the brain with the establishment of new pathological interneuronal relationships. Cognitive impairment depends on the lesion of the hippocampus. Thus, lesions of the left hippocampus cause a much more pronounced decrease in the level of verbal learning, while atrophy of the right hippocampus is characterized by a lack of nonverbal learning and memory. The cognitive functions of patients with epilepsy are

Table 4

The results of testing cognitive functions, selective attention, anxiety and depression level before and after the cognitive training course and psychoeducation

\begin{tabular}{|l|c|c|c|c|c|c|}
\hline \multirow{2}{*}{ Criteria } & \multicolumn{2}{c|}{ PG 1 $(\mathrm{n}=30)$} & \multicolumn{2}{c|}{ PG 2 $(\mathrm{n}=33)$} & \multicolumn{2}{c|}{ PG $(\mathrm{n}=33)$} \\
\cline { 2 - 8 } & before & after & before & after & before & after \\
\hline MoCA & 18.93 & 20.33 & 20.30 & 21.03 & 20.58 & 20.36 \\
\hline Quality of Life Scale & 67.2 & 69.97 & 66.94 & 68.15 & 78.06 & 79.06 \\
\hline Münsterberg's test & 9.4 & 10.03 & 9.18 & 9.45 & 10.06 & 10.21 \\
\hline Hamilton Anxiety Rating Scale & 23.09 & 11.64 & 15.34 & 11.07 & 6.39 & 9 \\
\hline Hamilton Depression Rating Scale & 6.83 & 5.13 & 7.43 & 5.11 & 7.91 & 5.42 \\
\hline
\end{tabular}


affected by heredity, organic damage to the brain, the presence of the epileptic process, treatment with antiepileptic drugs, the particular patient condition and personality traits. The active interaction of the above factors leads to the cognitive function impairment of each patient [6].

Differences in the cognitive status of the patient directly depend on the form of epilepsy and the type of seizures. Generalized tonic-clonic seizures provoke more significant cognitive impairment [7]. Thus, a generalized tonic-clonic attack can lead to decreased attention lasting up to 24 hours [8]. In patients with complex partial seizures, such changes are likely to last less time than in generalized tonic-clonic seizures, but it is clear that in patients with frequent seizures, this phenomenon significantly affects cognitive func-tioning [6].

The presence of psychiatric comorbidity is another important factor that influences patients' cognitive functioning. Firstly, some mental disorders, such as those associated with neuropsychological deficits [9]. Several studies have found dysfunction in the contour of the orbitofrontal loop in patients with mood disorders, which leads to a specific picture of impaired executive function and attention [10]. Secondly, in some cases, patients with mental disorders may have a poor understanding of their cognitive abilities, especially in mood disorders and anxiety disorders, for which cognitive complaints are an integral part [11].

There is no doubt about the effect on the cognitive functions of patients with epilepsy of some anticonvulsants, whose effectiveness is directly dose-dependent. According to the findings of a cohort study of a large group of patients, cognitive disorders observed in adults with epilepsy reflect the cumulative effect of epileptic processes and low premorbid cognitive ability [12]. Researchers single out four clinical variants of moderate cognitive impairment $[13,14]$ :

- amnestic monofunctional type - with selective memory impairment with relative preservation of other cognitive functions;

- amnestic multifunctional type, which is characterized by a combination of memory impairment and other cognitive impairments;

- multifunctional type without memory impairment, characterized by multiple cognitive impairments with relatively preserved memory;

- monofunctional non-amnestic type, characterized by the presence of a deficiency of one of the cognitive functions without memory impairment.

Cognitive impairments may manifest themselves to varying degrees, depending on which they can be classified as mild, moderate, severe and subjective cognitive impairments that are precursors to the further development of cognitive decline. Simultaneously, they may not be objectively confirmed during testing of patients. Most often, drugs are used to treat epilepsy, and if they are ineffective - other therapies, including surgery, which reduce the activity of epileptic foci. However, they are not always effective. According to the statistics, the number of people who do not receive the proper effect of therapy has not changed over the past two decades, and this share is about $30 \%$ of all patients.

Nowadays, we have the following nonpharmacological methods of correction: diet, physical exercises, cognitive training including cognitive stimulation, psychological and behavioural correction methods, psychotherapy (cognitive behavioural therapy, art therapy, music therapy etc.), meditation, and yoga.

When using those methods, cognitive functions may improve owing to neuroplasticity the brain's ability to reorganize itself physically by forming new neural connections in response to the surrounding $[15,16]$.

Everyday cognitive activities, in particular, learning new things, promote the establishment of new neuronal connection alongside preserving the old ones, which is in itself protection against the development of cognitive impairments [17].

Cognitive training, conducted through the implementation of specific programs and methods, aim to train memory, attention and other cognitive functions so as to maintain intelligence, develop particular cognitive abilities and to teach compensation and recovery strategies. There are two types of cognitive training: compensatory and recovery [18].

Compensatory cognitive training is aimed at teaching patients to learn new strategies of task solving, enhancing thereby their cognitive abilities. The following strategies are applied: data visualization, distribution by categories, and the use of external hints.

In recovery cognitive training, we implement the measures that aim to improve impaired cognitive functions. During the training that is aimed at particular task resolving, the development of relevant abilities arises. Classical training, cognitive stimulation and online training have been conducted both ways, individually and in groups.

According to the studies, cognitive tasks such as: written and oral calculations, reading, writing, spatial construction may brake epileptiform EEGdischarges in $64 \%$ of cases and provoke them in $7.9 \%$ [1]. Those results enable to theoretically 
assume the possibility to create specific cognitive tasks for inhibition of epileptiform activity, and also the possibility to change those cognitive activities, which cause epileptiform discharges, thus reducing the frequency of epileptic seizures. Such cognitive and behavioural measures could also evoke long-lasting changes in excitability [19].

According to the findings of a large randomized controlled study [20], the application of a motivational interview, combined with additional behavioural correcting methods, effectively improves patients' observance of a mode of reception of medication, as compared with controls over 3 and 6 months of observation. In the group with motivational interviews, researchers could also notice a decrease in seizures' severity, improvement in patients' quality of life and an increase of effectiveness of medication within therapeutic and sub-therapeutic range, after improvements of psychological indicators [20].

When applying modified (group-dependent) methods of cognitive behavioural therapy in the group aged 60 and over, the frequency of epileptic fell reduced significantly, as compared with another group where the control of relaxation was used. The result remained unchanged even over three months after treatment. Moreover, both groups witnessed an improvement of psychological indicators such as depression, dysthymia, psychosocial functions and psychological adaptation [21].

\section{Conclusions}

Our findings demonstrate that compared to the control group of healthy persons, patients with epilepsy show improvement in their cognitive decline, anxiety and depressive disorders. Cognitive online training appears to be effective for the patients with epilepsy. The findings of the study point to a more significant improvement of patients' cognitive functioning provided the use of psychoeducation and cognitive training methods along with anticonvulsant therapy compared to the application of cognitive training only.

The results of this research show the need for further study of the factors that influence the occurrence and progression of cognitive disorders, the development and implementation of training aimed to improve cognitive functions and prevent the progression of cognitive disorders. In modern conditions, online training of cognitive functions deserves to be introduced as part of the system of social rehabilitation of patients with epilepsy and cognitive disorders.

\section{Declarations:}

\section{Statement of Ethics}

The authors have no ethical conflicts to disclosure.

\section{Consent for publication}

All authors give their consent to publication. Disclosure Statement

The authors have no potential conflicts of interest to disclosure.

\section{Funding Sources}

This study was not supported by any grants from public, commercial or other sectors

\section{Data Transparency}

The data can be requested from the authors.

\section{References}

1. Sen, A., Capelli, V., \& Husain, M. (2018). Cognition and dementia in older patients with epilepsy. Brain, 141(6), 1592-1608. doi: 10.1093/brain/awy022

2. Helmstaedter, C. (2013). The impact of epilepsy cognitive function. J Neurol Neurosurg Psychiatry, 84, 5-15. doi: 10.1136/jnnp-2013-306103.14

3. Martsenkovskiy I. A., \& Martsenkovskaya, I. I. (2015). Rasstroystva psikhiki i povedeniya pri epilepsiyakh: klinicheskaya tipologiya i terapevticheskie strategii [Mental and behavioral disorders in epilepsy: clinical typology and therapeutic strategies]. NeuroNEWS, 8, 21-33.

4. Gaitatzis, A., Trimble, M. R., \& Sander, J. W. (2004). The psychiatric comorbidity of epilepsy. Acta Neurol Scand, 110(4), 207-220. doi: 10.1111/j.1600-0404.2004.00324.x

5. Gandy, M., Karin, E., Fogliati, V. J., McDonald, S., Titov, N., \& Dear, B. F. (2016). A Feasibility Trial of an Internet-Delivered and Transdiagnostic Cognitive Behavioral Therapy Treatment Program for Anxiety, Depression, and Disability Among Adults With Epilepsy. Epilepsia, 57(11), 1887-1896. doi: 10.1111/epi.13569

6. Mula, M., \& Trimble, M. R. (2009). Antiepileptic drug-induced cognitive adverse effects: potential mechanisms and contributing factors. CNS Drugs, 23(2), 121-137. doi: 10.2165/00023210-200923020-00003

7. Dodrill, C. B. (1986). Correlates of generalized tonic-clonic seizures with intellectual, neuropsychological, emotional and social function in patients with epilepsy. Epilepsia, 27(4), 399-411. doi: 10.1111/j.1528-1157.1986.tb03559.x

8. Aldenkamp, A. P., \& Bodde, N. (2005). Behaviour, cognition and epilepsy. Acta Neurol Scand Suppl, 112(s182), 19-25. doi: 10.1111/j.1600-0404.2005.00523.x 
9. Millan, M. J., Agid, Y., Brune, M, Bullmore, E. T., Carter, C. S., Clayton, N. S., ... \& Young L. J. (2012). Cognitive dysfunction in psychiatric disorders: characteristics, causes and the quest for improved therapy. Nat Rev Drug Discov, 11(2)2, 141-168. doi: 10.1038/nrd3628

10. Kanner, A. M., Wuu, J., Faught, E., Tatum, W. O. 4th, Fix, A., \& French, J. A. (2003). A past psychiatric history may be a risk factor for topiramate-related psychiatric and cognitive adverse events. Epilepsy Behav, 4(5), 548-552. doi: 10.1016/j.yebeh.2003.07.007

11. Unterberger, I., Zamarian, L., Prieschl, M., Bergmann, M., Walser, G., Luef, G., ... \& Delazer, M. (2018). Risky Decision Making in Juvenile Myoclonic Epilepsy. Front Neurol, 9, 195. doi: 10.3389/ fneur.2018.00195

12. Osler, M., Mortensen, E. L., Christensen, K., \& Christensen, G. T. (2018). A bidirectional association between cognitive ability in young adulthood and epilepsy: a population-based cohort study. Int J Epidemiol, 47(4), 1151-1158. doi: 10.1093/ije/dyy018

13. Strelnikova, I.N., \& Polyakova, A.V. (2012). Struktura depressivnykh rasstroystv u bol'nykh epilepsiey [The structure of depressive disorders in patients with epilepsy]. Ukrajnskij visnyk psyhonevrologij, 20(3), 226.

14. Holmes, G. L. (2015). Cognitive impairment in epilepsy: the role of network abnormalities. Epileptic Disord, 17(2), 101-116. doi: 10.1684/epd.2015.0739

15. Wilson, R. S., Scherr, P. A., Schneider, J. A., Tang, Y., \& Bennett, D. A. (2007). Relation of cognitive activity to risk of developing Alzheimer disease. Neurology, 69(20), 1911-1920. doi: 10.1212/ 01.wnl.0000271087.67782.cb

16. Kolb, B., \& Gibb, R. (2008). Principles of neuroplasticity and behavior. In: D. Stuss, G. Winocur, I. Robertson. Cognitive neurorehabilitation: Evidence and Application. Cambridge University Press, 621. doi: $10.1017 / \mathrm{CBO} 9781316529898.003$

17. Naumenko, A. A., Gromova, D. O., \& Preobrazhenkaya, I. S. (2017). Kognitivnyy trening i reabilitatsiya patsientov s kognitivnymi narusheniyami [Cognitive Training and Rehabilitation of Patients with Cognitive Impairments]. Doctor Ru, 11, 31-38.

18. Rodakowski, J., Saghafi, E., Butters, M. A., \& Skidmore, E. R. (2015). Non-pharmacological interventions for adults with mild cognitive impairment and early stage dementia: An updated scoping review. Mol. Aspects Med, 43-44, 38-53. doi: 10.1016/j.mam.2015.06.003.

19. Matsuoka, H., Nakamura, M., Ohno, T., Shimabukuro, J., Suzuki, T., Numachi, Y., \& Awata, S. (2005). The role of cognitive-motor function in precipitation and inhibition of epileptic seizures. Epilepsia, 46(Suppl 1), 17-20. doi: 10.1111/j.0013-9580.2005.461006.x

20. Pakpour, A. H., Gholami, M., Esmaeili, R., Naghibi, S. A., Updegraff, J. A., Molloy, G. J., \& Dombrowski, S. U. (2015). A randomized controlled multimodal behavioral intervention trial for improving antiepileptic drug adherence. Epilepsy Behav, 52(Pt A), 133-142. doi: 10.1016/j.yebeh.2015.08.036.

21. Tan, S. Y., \& Bruni, J. (1986). Cognitive-behavior therapy with adult patients with epilepsy: a controlled outcome study. Epilepsia, 27(3), 225-233. doi: 10.1111/j.1528-1157.1986.tb03533.x

22. Carson, N., Leach, L., \& Murphy, K. J. (2018). A re-examination of Montreal Cognitive Assessment (MoCA) cutoff scores. Int J Geriatr Psychiatry, 33(2), 379-388. doi: 10.1002/gps.4756.

23. Ciesielska N, Sokolowski R, Mazur E, Podhorecka M, Polak-Szabela A, \& Kedziora-Kornatowska K. (2016). Is the Montreal Cognitive Assessment (MoCA) test better suited than the Mini-Mental State Examination (MMSE) in mild cognitive impairment (MCI) detection among people aged over 60? Metaanalysis. Psychiatr Pol, 50(5), 1039-1052. doi: 10.12740/PP/45368.

24. Nasreddine, Z. S., Phillips, N. A., Bedirian, V., Charbonneau, S., Whitehead, V., Collin, I., ... \& Chertkow H. (2005). The Montreal Cognitive Assessment, MoCA: a brief screening tool for mild cognitive impairment. J Am Geriatr Soc, 53(4), 695-699. doi: 10.1111/j.1532-5415.2005.53221.x

25. Poythress, N. G., \& Blaney, P. H. (1978). The validity of MMPI interpretations based on the Minimult and the FAM. J Pers Assess, 42(2), 143-147. doi: 10.1207/s15327752jpa4202_5

26. Obeid, S., Hallit, C. E., Haddad, C., Hany, Z., \& Hallit, S. (2018). Validation of the Hamilton Depression Rating Scale (HDRS) and sociodemographic factors associated with Lebanese depressed patients. Encephale, 44(5), 397-402. doi: 10.1016/j.encep.2017.10.010

27. Williams, J. B. (1988). A structured interview guide for the Hamilton Depression Rating Scale. Arch Gen Psychiatry, 45(8), 742-747. doi: 10.1001/archpsyc.1988.01800320058007

Received: 01-Feb-2020

Accepted: 18-Jun-2020 